\title{
CULTURAL EUROPEAN ROUTES: TRANSFER EXPERIENCES, SHARE SOLUTIONS (CERTESS)
}

\author{
S. Capp ${ }^{\text {a }}$ \\ ${ }^{a}$ European Institute for Cultural Routes, Abbaye de Neumünster, 28 rue Münster, L.2160 Luxembourg \\ sorinacapp@culture-routes.lu
}

KEY WORDS: Cultural routes; Council of Europe; Best practices; Governance tools; Route plans; Cultural tourism.

\begin{abstract}
:
This paper deals with the building-up of a methodological framework on how to develop and manage Cultural Routes (CRs) by making use of route development best practices and governance instruments targeted to foster sustainable cultural tourism. CRs are intended by the Council of Europe as "historical lines interconnecting one or more regions and organized around topics whose historical, artistic or social interest proves to be European, either because of the geographical layout of the route, or due to its contents and significance". Most ECRs lack comprehensive methodologies and governance instruments to implement effective strategies at regional level. The draft methodology is intended to be tested and detailed under a European project (CERTESS) where partners, while designing their CR Route Plans, will: a) adopt customised Best Practices; b) develop and adopt well-suited governance tools; c) promote local enterprises and products along their routes by use of innovative immaterial services including ITC. CERTESS partners intend to make their activities sustainable by integrating their Plans into a ECR strategy for establishing Europe as a "first cultural tourism destination in the world".
\end{abstract}

\section{INTRODUCTION}

\subsection{Council of Europe \& EICR}

1.1.1 Council of Europe. The Council of Europe (CoE), with its Cultural Routes Programme (CRP) launched in 1987, aims at demonstrating how the heritage of the different countries and cultures of Europe contributes to a shared cultural heritage, and intends to put into practice the fundamental $\mathrm{CeO}$ principles: human rights, cultural democracy, cultural diversity and identity, dialogue, mutual exchange and enrichment across boundaries and centuries.

In December 2010, the Committee of Ministers of the Council of Europe adopted Resolution CM/Res(2010)53 establishing an Enlarged Partial Agreement on Cultural Routes (EPACR) to enable closer co-operation between states particularly interested in the development of $\mathrm{CR}$, while dictating the EPA rules for $\mathrm{CR}$ certification. Resolution CM/Res(2010)53 ruled on EPA statute and organs.

The EPACR seeks to reinforce the potential of CR for cultural co-operation, sustainable territorial development and social cohesion, with a particular focus on themes of symbolic importance for European unity, history, culture and values and the discovery of less well-known destinations.

\subsubsection{EICR}

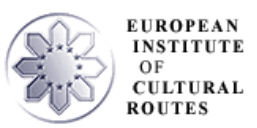

The European Institute of Cultural Routes (EICR) is a a nonprofit association established in July 1997. Since 1998, EICR has been in charge of ensuring the continuity but also the development of the CoE's CRP.
In the framework of EPACR, EICR acts as a technical body for operational purposes. Its role is to examine applications for new projects, to monitor activities in the field and co-ordinate the work of partner organisations and to disseminate and archive information documents.

EICR is therefore in contact with many countries, regions, municipalities, NGOs, European institutions, etc. and with many of them has established long-term cooperation.

In the past - after meetings, projects, seminars, workshops to analyze governance and funding rules - one of the main conclusions was that the regional level is an essential key for trans-border ECRs since the majority of ECRs networks are composed by regions, districts or clusters of municipalities, even if the route goes through several countries.

EICR prepared in the past a report for Congress of Local and Regional authorities (CPLRE of Council of Europe) reflected in the adopted resolution on 'Cultural tourism, element of promotion of sustainable development at local and regional level'.

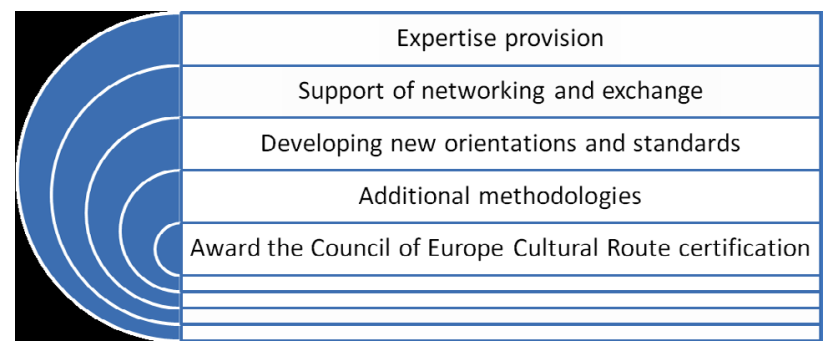

Figure 1. Policy-making and standard setting

1.1.3 Present constraints. To date 29 CoECRs have been certified. Most of the 29 certified CoECRs show:

- unclear definition of governance concept (integration of activities, management, coordination, etc.); 
- too wide diversity of organizations involved in the CR governance (non-profit agencies, associations, foundations, etc.) and mostly SMEs;

- lack of common standards, programmes and quality control tools;

${ }^{\circ}$ lack of managerial and training models to facilitate sustainable and competitive development of the CRs;

${ }^{\circ}$ insufficient understanding of how a CR system works (what is the demand, how fragmented is the supply, etc.).

This leads to an insufficient economic exploitation of the routes and territories concerned, with a resulting limited contribution to territorial cohesion.

The identification of new CRs lacks guided access to well recognized ICT tools (e.g. GIS marking of routes) thus achieving non-homogeneous nor comparable results (f.i. route marking and signalling tend to vary from one route to another, sometimes causing misleading interpretations and consequent inconveniences to travellers).

There is also a limited evidence of good practice experiences readily accessible to $\mathrm{CR}$ actors. Previous experience reveal, furthermore, that identification and dissemination of good practices is often an uncrossed threshold to effectively transferring them to other regions by replication and adaptation. The need of a concerted methodology for the whole process of $\mathrm{CR}$ development is therefore recognised as of priority.

\subsection{CERTESS project}

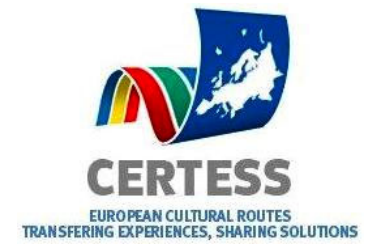

1.2.1 Standard reference methodology. CERTESS project stems from the necessity to develop a standard methodology for ECR development \& certification by addressing the present context deficiencies towards a more coherent system of route identification, structuring, fruition and preservation.

1.2.2 Pre-project activities. Many regions attended the 2010 European Tourism Day, organized by the EC on the CR topic, and 3 other EU meetings were held on the same subject.

EICR \& the Ministry of Culture of Luxembourg decided to propose to some of the participating regions to prepare an INTERREG IVC project, to identify critical issues and to find common solutions to be shared with other regions interested in implementing CRs.

Ad-hoc meetings were subsequently held:

- at the European Conference on the Via Francigena Route, in Rome (11 Feb 2011),

- at NECSTouR in Brussels on 23 Feb 2011,

- at the European Conference in Luxembourg of 28-29 March 2011 on the impact of cultural routes on SME's innovation and competitiveness, attended by representatives of $\mathrm{CoE}$, the DG Enterprise and Industry of the EC, the European Parliament, the EICR, experts and coordinators of several CRs, etc.

CERTESS project partners were selected out of those who attended the said meetings \& events and are all either involved in CR management or have expressed their interest to develop new CRs.

1.2.3 The INTERREG IVC 2011 call. CERTESS project proposal was formulated and submitted under Priority 2 and, in particular, the sub-theme "Cultural Heritage and Landscape" of the INTERREG IVC (2007-2013 Programme Period) $4^{\text {th }}$ Call ended on 1st April 2011. The project was successfully selected for funding in December 2011 and started its operations in April 2012. Its completion is envisaged in November 2014.

1.2.4 Aims of CERTESS project. It has been agreed to have the regional level as a reference level for CRs promotion, in order to:

- help regions to cooperate better,

${ }^{\circ}$ have an exchange of experiences,

${ }^{\circ}$ share solutions,

with the aim to implementing CRs as an important element of European integration.

An interregional project is, in fact, one of the solutions to ensure regional exchange and agree on common definitions, standards, indicators, coaching and tutoring methods.

CERTESS project is deeply rooted in the past and ongoing involvement of project partners in promoting CRs and built on the well-placed EICR position as an overseeing agent of route recognition and promotion, aims at adding value to CRs and promoting them as part of a variegated and multi-content network in the whole Europe.

\subsection{CERTESS partnership}

CERTESS project is implemented by 12 partners from $10 \mathrm{EU}$ Member Countries.

\begin{tabular}{|l|l|l|}
\hline Partner & Location & Country \\
\hline $\begin{array}{l}\text { European Institute of } \\
\text { Cultural Routes }\end{array}$ & Luxembourg & Luxembourg \\
\hline Lazio Region & Rome & Italy \\
\hline Dept of Local Government & La Valletta & Malta \\
\hline Salzburg Research & Salzburg & Austria \\
\hline $\begin{array}{l}\text { Tourism Agency of the } \\
\text { Balearic Islands (ATB) }\end{array}$ & Palma & Spain \\
\hline $\begin{array}{l}\text { Regional Ministry of } \\
\text { Tourism, Commerce \& Sport } \\
\text { della Junta de Andalucia }\end{array}$ & Sevilla & Spain \\
\hline $\begin{array}{l}\text { Karlsruhe Institute of } \\
\text { Technology }\end{array}$ & Karlsruhe & Germany \\
\hline Zlin Region & Zlin & Czech Repub. \\
\hline Admin.ve District of Gorlice & Gorlice & Poland \\
\hline Ministry of Culture & Luxembourg & Luxembourg \\
\hline $\begin{array}{l}\text { Sibiu County Tourism } \\
\text { Association }\end{array}$ & Sibiu & Romania \\
\hline $\begin{array}{l}\text { Jamk University of Applied } \\
\text { Sciences }\end{array}$ & Jyvaskyla & Finland \\
\hline
\end{tabular}

Table 2. CERTESS project partners

\section{METHODOLOGY}

\subsection{Objectives}

2.1.1 General objectives. The methodology to be developed and tested under CERTESS project aims at establishing a European reference model procedure for:

- defining, structuring and promoting a sustainable CR, thus contributing to Europe 2020 tourist destination target;

- setting up shared tools for EU regions to improve their socio-economic setup and competitiveness while preserving the local cultural heritage; 
- contributing to implementing the EPA-CR of the CoE.

2.1.2 Specific objectives. Specific objectives of methodology application to specific CR initiatives are here identified.

A. Knowledge-base Development. Creating a knowledge-base in the field of valorisation of cultural heritage and its socioeconomic context, by identifying and documenting aspects of geo-historical evidence relative to a specific CR theme and its associated cultural heritage local assets.

B. Capacity Building. Building an CR-based capacity by: (i) by strengthening the guidance role of regional \& local bodies as policy makers co-acting with stakeholders; (ii) reinforcing public-private cooperation; promoting local CR-related enterprises \& products by enhancing their integration and quality level.

C. Sustainability. Contributing to ensure the economic and environmental sustainability of CR-related activities. Economic stakeholders along the route need to acquire a global understanding on how the route system works, what is their role to play and how to satisfy travellers' expectations, while also tackling the environmental issues deriving from $\mathrm{CR}$ fruition.

\subsection{Methodology stages}

The reference methodology is preliminarily outlined in this para. 2.2 and in Figure 3, with a special account paid to the Rules established in Resolution $\mathrm{CM} / \operatorname{Res}(2010) 52$ and its Appendix. The conceptual structure is preliminarily organised in 6 Sections intended somehow also a sequence of CR development stages. CERTESS project shall experiment the application of most components and achieve evaluation results useful for the optimisation of the methodology, in view of a possible routine application in future.

2.2.1 CR theme development. Section 1 deals with the geohistorical and cultural background and character that lay behind and justify the theme proposed for a new CR. Themes are to be selected among the priority fields of action indicated in part II Appendix to Resolution CM/Res(2010)52, namely:

1. Co-operation in research and development

2. Enhancement of memory, history and European heritage

3. Cultural and educational exchanges for young Europeans

4. Contemporary cultural and artistic practice.

An important element is represented by the setting up of a common Glossary of terms and definitions relevant to $\mathrm{CR}$ establishment and development.

In general, each $\mathrm{CR}$ promoter shall:

(1.1) identify the theme of interest and ascertain the geographic transnational alignment in case of a physical CR or its reference area in case of a virtual CR;

(1.2) collect available historical-cultural documentation on the proposed CR theme;

(1.3) organise the theme reference contents into a specific webbased database.

2.2.2 CR network setup. Section 2 deal with the structuring of permanent relations, legal and operational, among all subjects involved or interested in the developing the selected CR both at transnational and at local regional level.

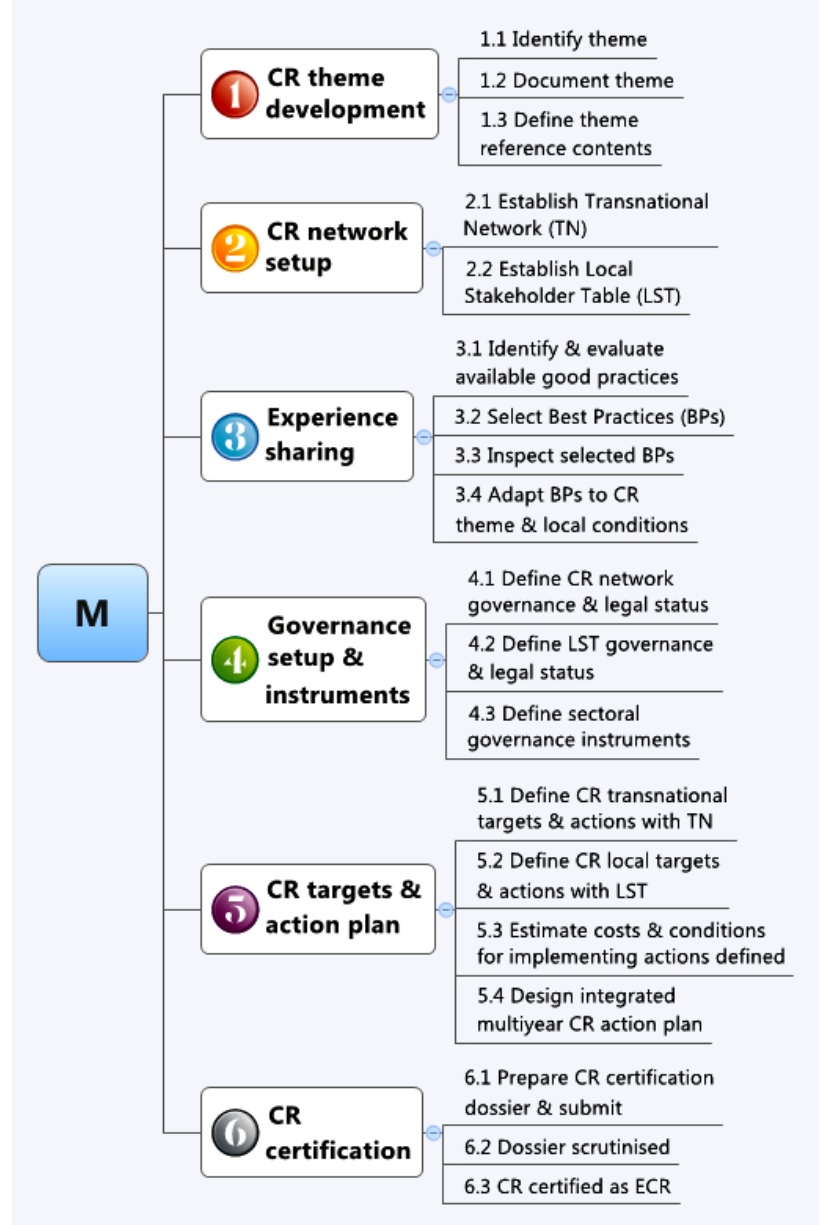

Figure 3. Methodology logical structure

In CERTESS each partner shall establish during project life a Local Stakeholder Table (LST) expected to:

- contribute to benchmarking the good practices identified by each partner at its local area level;

- recommend those good practices to be selected as Best Practices (BPs);

- organise local dissemination/evaluation seminars to identify suitable governance instruments;

- assist in designing the Route Implementation Plan (RIP);

- contribute to mobilize local socio-economic \& financial resources to support the RIP implementation;

- cooperate in making project outputs sustainable in the medium-term.

The stake-holder analysis consists of a 4 step process:

1. identify key stakeholders;

2. assess stakeholders' interests and the potential impact of the CR initiative on those;

3. assess stakeholders' influence and importance;

4. outline each stakeholder's participation strategy.

Stakeholders are identified by utilising a power/interest matrix to map out local stake-holding members and classify them by power exerted over project-related decisions and by interest shown versus the $\mathrm{CR}$ initiative or a specific objective/topic.

Relevant partners will endeavour to promote after project completion a Transnational Network (TN) on the selected CR theme. 
2.2.3 Experience sharing. Section 3 is the core of the methodology and the basis for final outputs. Relevant experiences are identified, analysed, reviewed, benchmarked so that resulting experiences of excellence are field-inspected, become subject for tutored transfer and eventually become the backbone of the actions to be planned.

In CERTESS the following is envisaged:

(3.1) Good practices are selected by cross-comparing similar experiences in different areas or implemented projects utilising a standard form with a related guideline and check-list to document the quality characteristics of the practice analysed.

(3.2) Practices of excellence (BPs) are preliminarily chosen among the previous ones.

(3.3) Site visits are made to partner regions to inspect BPs identified.

(3.4) Benchmarking sessions are held to confirm the chosen BPs and to select at least $1 \mathrm{BP}$ for each thematic area for replication/adaptation. In addition, site tutoring sessions are performed in receiving partner regions by partners that have developed a specific BP among those selected. An expert team cooperates to transfer a specific BP by establishing a replication/adaption process to suit local conditions.

2.2.4 Governance instruments. Section 4 tackles only governance instruments that relate to the establishment/ development of a CR and to those activities/subjects represented in a TN or a LST.

In CERTESS local dissemination/evaluation seminars are organized by LSTs to:

(4.1) define CR network governance and legal status;

(4.2) define LST governance and legal status;

(4.3) define sector governance instruments to be applied for $\mathrm{CR}$ development.

2.2.5 CR targets \& action plan. Section 5 concerns with the design of targets, strategies and actions suitable for establishing, developing and having certified a specific thematic CR selected by the promoting $\mathrm{TN}$.

CR transnational targets and consequent actions to be implemented are defined at TN level.

In CERTESS the following is envisaged:

(5.1) CR local targets and consequent actions to be executed are agreed at LST level.

(5.2) Costs and conditions for implementing the defined actions are estimated.

(5.3) A Route Implementation Plan (RIP) is developed for each $\mathrm{CR}$, thus setting the basis for a multiregional scheme of development activities regarding each CR network. Each RIP shall provide a concrete roadmap for $\mathrm{CR}$ enhancement in all participating regions by institutional engagement and stakeholders' involvement and shall consist of:

- networking-governance-sectoral actions to be executed,

- multiyear budget for action implementation,

- financing lines related to the RIP as a whole or to individual sectoral actions (cultural services, SMEs, etc.).

2.2.6 CR certification. In Section 6 steps are defined for the new CR post-establishment certification as ECR.

This eventual stage (not envisaged in CERTESS) is to be performed only once a specific new $\mathrm{CR}$ has been firmly established and important actions included in the RIP have been implemented. Once this is done, then the following steps follow:
(6.1) A CR certification dossier is compiled in compliance with $\mathrm{CoE}$ requirements and EICR directives.

(6.2) The CR dossier is then scrutinised by EICR. If important aspects are lacking, then the dossier is sent back for upgrading. If the dossier is satisfactory, then EICR recommends for the $\mathrm{CR}$ certification to Governing Board of the EPA in accordance with CM/Res(2010)52.

(6.3) The CR is certified as a CoECR.

\subsection{Outputs and Results}

2.3.1 Outputs. Main expected outputs are those indicated in italics hereunder. Those foreseen in CERTESS are indicated in quantitative terms are:

1. CR theme development. CR themes developed. Geographic and historical-cultural databases established.

2. CR network setup. CR Transnational Network defined; 11 Local Stakeholder Tables established.

3. Experience sharing. 30 good practices documented; 10 BPs selected; 4 site visits performed; 2 benchmarking sessions held, 4 site tutoring sessions held.

4. Governance setup \& instruments. 11 local dissemination/ evaluation seminars; 80 governance instruments initially identified for 4 thematic areas; 11 policies finally earmarked.

5. CR targets \& action plans. 11 Route Implementation Plans developed.

2.3.2 Results. Main expected direct results are:

1. CR theme development, with the associated result of an historical and cultural enriched awareness.

2. CR network setup, with the associated results and an increasing cooperation at interregional level in Europe.

3. Experience sharing, based on the joint recognition and exchange of consolidated practices in CR development.

4. Governance setup \& instruments, capable to meet concrete needs or contribute to remove obstacles or critical issues as identified.

5. CR targets \& action plans. strengthening of project planning capacities in the perspective of a sustainable development at inter-sector level. The plan, thus, represents a concrete roadmap for the CR enhancement.

6. CR certification. An overall result is the strengthening of cooperation between EICR \& EU regions through the shared adoption of standardised methodology, procedures, contents and multi-sector action models.

CERTESS envisages results primarily related to point 3,4 and 5 above.

\section{CONCLUSIONS}

\subsection{Innovative and Original Character}

The above methodology, applied in CERTESS, shows an innovative character and approach, as it tackles in a coparticipatory manner the issue of cultural route in relation to economic promotion of territories intersected by physical itineraries.

No efforts are evident of on-going initiatives aimed at streamlining policy matters to include promotion of cultural routes at regional or sub-regional level. In other words, a clear gap is evident between declarations at national and transnational level, as well as European level, and regional approach and implementation policies relevant to a number of specific themes or topics such as assurance of quality services and their continuous improvement as well as material and immaterial 
enhancement of routes including landscape and environment in special way as essential components of the route.

Development of Route Implementation Plans for the governance of cultural routes is CERTESS's most innovative aspect. The project aims to identify and tackle by a strategic format some of the main topics of cultural heritage governance, namely: (a) setting or expanding a cultural route, (b) providing necessary infrastructure support (material and immaterial), (c) ensuring quality and safety standard for their fruition. The project thus increases the competitiveness and sustainability of the cultural tourism in EU territories intersected by cultural routes and their territorial cohesion through several integrated action tools.

\subsection{Impact and added values}

CERTESS acknowledges the INTERREG IVC Programme emphasis on the importance to distinguish between practice transfers and policy impacts.

Transfer of practices constitutes only one aspect of the benefits of interregional cooperation having European relevance and value, whereas exchange and transfer of experience can also lead to more structural changes within the regions. Such structural changes are deemed to be part of the Route Plan and the medium-term perspective for its implementation constitutes also the time-based scenario for impacts and added values to materialise.

\subsection{Future Developments}

3.2.1 Sustainability. Sustainability is not relevant for the CERTESS partnership as a whole but, instead, for the CRs identified and developed as result of partners' joint cooperation and it shall be dealt with after having established the TN associated to each CR.

EICR, as depository of experiences relating to the 29 ECRs already approved, aims at fostering a larger use of project outputs among all participants to each individual route, with the purpose of streamlining procedures and instruments. To this aim, EICR will ensure that the knowledge \& knowhow base platform established will be updated also after project end, together with data and information concerning new applications in new regions to promote diffusion and replication. EICR is best placed to ensure that this is continued in future.

In addition, the development of RIPs with the active involvement of local stakeholders and tourist promoters in the project regions will be the main medium-term guarantors for sustaining the project results. To a larger replication effect, final conferences in each partner region will aim to lay the foundation for enlargement of cooperation and replication of practices also in other regions along the reference CR.

3.2.2 Methodology. EICR / CoE will consider reviewing the methodology developed under CERTESS and developing it into reference guidelines to be adopted by EICR in the framework of the EPA strategy and applied both to CRs newly developed or being consolidated.

3.2.3 Tutoring. EICR may consider establishing a regular tutoring service to support route developers/enhancers upon request.
3.2.4 Experience sharing. CERTESS partnership will liaise with BPs information and dissemination centres (such as Culture Watch Europe, NECSTouR, Compendium, IFACCA, ERIcarts and his associated centres of excellence, etc.) to contribute to the wealth of monitoring standards, developments and trends in cultural policy. Synergic cooperation will contribute to increasing the multiplier impact in other contexts.

3.2.5 Spin-off projects. Relations already developed under CERTESS and within the institutional activity of EICR are expected to be instrumental in conceiving and developing future European spin-off projects and local sector plan/actions to be funded with other financial resources.

3.2.6 Quality. Promoting gradually a European-level quality certification procedure and label, subject to periodic confirmation, will reinforce the networking strategy of cooperation.

\section{REFERENCES}

\section{References from websites:}

Council of Europe, 2010a. Resolution CM/Res(2010)52 on the rules for the award of the "Cultural Route of the Council of Europe" certification. https://wcd.coe.int/ViewDoc.jsp? Ref= $\mathrm{CM} / \operatorname{Res}(2010) 52 \&$ LangGovernance\%20instrumentsuage=lanE nglish $\&$ Site $=\mathrm{CM} \&$ BackColorInternet $=\mathrm{C} 3 \mathrm{C} 3 \mathrm{C} 3 \&$ BackColorIntr anet=EDB021\&BackColorLogged $=$ F5D383 (accessed 13 Aug. 2012).

Council of Europe, 2010b. Resolution CM/Res(2010)53 establishing an Enlarged Partial Agreement on Cultural Routes. https://wcd.coe.int/ViewDoc.jsp?id=1719265\&Site= CM\&BackColorInternet $=$ C3C3C3\&BackColorIntranet $=$ EDB02 1\&BackColorLogged=F5D383 (accessed 13 Aug. 2012).

Council of Europe, 2012. Impact of European Cultural Routes on SMEs' innovation and competitiveness (provis. ed.). http://www.coe.int/t/dg4/cultureheritage/ culture/routes/ StudyCR_en.pdf (accessed 13 Aug. 2012).

\section{ACKNOWLEDGEMENTS}

CERTESS, 1191R4, European Cultural Routes - Transfer Experiences, Share Solutions, Sorina Capp, Deputy Director of the European Institute for Cultural Routes (Luxembourg). It is a project funded by the EU's European Regional Development Fund, through the INTERREG IVC Programme 2007-2013 The Interregional Cooperation Programme INTERREG IVC helps Regions of Europe work together to share experience and good practice in the areas of innovation, the knowledge economy, the environment and risk prevention. 
